DOI 10.12957/demetra.2014.6246

\title{
A atuação profissional do nutricionista no contexto da sustentabilidade
}

\section{The professional role of nutritionists in the context of sustainability}

Camilla Ceylão Daher Naves'

Elisabetta Recine ${ }^{2}$

${ }^{1}$ Núcleo de Segurança Alimentar e Nutricional do Centro Oeste. Brasília, DF, Brasil.

${ }^{2}$ Departamento de Nutrição, Faculdade de Ciências da Saúde. Universidade de Brasília. Brasilia, DF, Brasil.

Correspondência / Correspondence Camilla Ceylão Daher Naves E-mail:milla.ceyla0@gmail.com

\section{Resumo}

O conceito de sustentabilidade pode ser definido como um equilíbrio que busca satisfazer as necessidades presentes, sem comprometer as das gerações futuras. O conceito está fundamentado em três dimensões: econômica, ambiental e social, que também fundamentam o conceito de segurança alimentar e nutricional. Diversos autores apontam as dificuldades de garantir tanto a segurança alimentar e nutricional como a sustentabilidade, mas consideram ambas como desafios possíveis. As dificuldades se relacionam ao modelo de sistema agroalimentar vigente e de desenvolvimento econômico e produtivo hegemônico. Tendo isso em vista, esclarecer as atribuições e contribuições do nutricionista para o alcance da sustentabilidade, investigando as concepções, valoração, aplicabilidade e dificuldades percebidas acerca do tema, permite fomentar o papel desse profissional na promoção de um futuro de qualidade social, ambiental e econômica. Portanto, o objetivo deste estudo é caracterizar a atuação profissional do nutricionista segundo aspectos relativos ao sistema agroalimentar e à sustentabilidade. $\mathrm{O}$ estudo tem natureza descritiva e transversal, com abordagem quantitativa, e foi realizado no período de março de 2011 a junho de 2012, quando 192 nutricionistas de todo o Brasil responderam ao questionário online. Os resultados apontam que a atuação profissional do nutricionista voltada para a sustentabilidade, ainda que considerada importante, é pouco desenvolvida, indicando a necessidade de mudanças na formação e atuação profissional, a fim de que este possa exercer papel-chave no alcance da sustentabilidade.

Palavras-chave: Nutricionista. Sustentabilidade. Nutrição e Sustentabilidade. Desenvolvimento Sustentável. Segurança Alimentar e Nutricional. 


\section{Abstract}

The concept of sustainability can be defined as a balance that seeks to meet present needs without compromising those of future generations. The concept is based on three dimensions: economic, environmental and social, which also underlie the concept of food and nutrition security. Several authors point out the difficulties of ensuring both food security and nutrition as sustainability, but consider both as potential challenges. The difficulties relate to current food system and the hegemonic model of economic and production development. Keeping this in view, clarifying the roles and contributions of nutritionists to achieve sustainability, investigating the concepts, valuation, applicability and perceived difficulties on the subject, increases the role of these professionals in promoting a future of social, environmental and economic quality. Therefore, the aim of this study is to characterize the professional performance of the nutritionist concerning aspects of the food system and sustainability. This is a descriptive and cross sectional study, using quantitative approach, and was conducted from March 2011 to June 2012, when 192 nutritionists throughout Brazil responded to the online questionnaire. The results indicate that the professional service of nutritionists focused on sustainability, although considered important, is poorly developed, indicating the need for changes in training and professional expertise, so that they can play key role in achieving sustainability .

Key words: Nutritionist. Sustainability. Nutrition and Sustainability. Sustainable Development. Food and Nutrition Security.

\section{Introdução}

A importância e a urgência das discussões acerca da sustentabilidade pautam-se nas evidências dos limites do modelo econômico e produtivo convencional. De acordo com Nascimento, " "o padrão de produção e consumo em expansão no mundo, principalmente nas últimas décadas, não tem possibilidade de perdurar". As evidências dos efeitos adversos provocados pela humanidade sobre o meio ambiente e os ecossistemas são preocupantes e, décadas atrás, desencadearam as discussões sobre a necessidade de um modelo de desenvolvimento sustentável. O que se observa são poucos avanços em termos de resultados, desde a Conferência ocorrida no Rio de Janeiro em 1992 até os dias de hoje. As propostas da Agenda 21 foram pouco ou nada cumpridas ${ }^{2}$ e os problemas a serem resolvidos atualmente continuam sendo os mesmos, mas em maiores proporções. ${ }^{3}$ 
O conceito de "sustentabilidade" começou a ser delineado em 1972, na Conferência das Nações Unidas sobre o Meio Ambiente Humano, em Estocolmo, e partia do princípio de que o uso dos recursos naturais para a satisfação das necessidades presentes não deveria comprometer a satisfação das necessidades das gerações futuras. Já o conceito de "desenvolvimento sustentável" surgiu em 1983, em meio às discussões da Comissão Mundial do Meio Ambiente e Desenvolvimento, e se oficializou em 1987, com a publicação do relatório Nosso Futuro Comum, sendo definido como "equilíbrio que procura satisfazer as necessidades da geração atual, sem comprometer a capacidade das gerações futuras de satisfazerem suas próprias necessidades". ${ }^{4}$ Para a Comissão, o conceito de desenvolvimento sustentável deve fundamentar as políticas públicas de forma que os objetivos do desenvolvimento econômico e social sejam definidos em termos de sustentabilidade. ${ }^{5}$

Percebe-se que o desenvolvimento sustentável está fundamentado em três dimensões: econômica, ambiental e social, ${ }^{5}$ que também fundamentam os conceitos de "sustentabilidade" e de "segurança alimentar e nutricional" (SAN). ${ }^{6}$ Para Maluf, ${ }^{6}$ a segurança alimentar e nutricional não depende apenas da existência de um sistema alimentar que garanta produção, distribuição e consumo de alimentos em quantidade e qualidade adequadas, mas que também não venha a comprometer a capacidade futura de produção, distribuição, consumo e condições ambientais favoráveis à vida. Desta forma, a sustentabilidade se insere oficialmente no conceito de SAN, que seria construído com complexidade em 2006. De acordo com a Lei no 11.346, de 15 de setembro de 2006, que cria o Sistema Nacional de Segurança Alimentar e Nutricional (SISAN), ${ }^{7}$ a segurança alimentar e nutricional "consiste na realização do direito de todos ao acesso regular e permanente a alimentos de qualidade, em quantidade suficiente, sem comprometer o acesso a outras necessidades essenciais, tendo como base práticas alimentares promotoras de saúde que respeitem a diversidade cultural e que sejam ambiental, cultural, econômica e socialmente sustentáveis".

O sistema alimentar é definido como uma cadeia de atividades que podem ser divididas em cinco etapas: produção, processamento, distribuição, consumo e disposição de resíduos. A produção diz respeito ao cultivo dos alimentos e criação de animais; o processamento se refere ao processo de transformação dos alimentos em produtos; a distribuição trata do armazenamento e transporte dos alimentos do local de produção aos mercados; o consumo é a fase na qual o alimento é adquirido, utilizado e consumido; e por fim, a disposição de resíduos é referente ao descarte final dos alimentos e seus subprodutos. ${ }^{8,9}$

Está cada vez mais claro que, em termos globais, este sistema se dá de forma ambientalmente insustentável, visto que todas suas etapas podem impactar de alguma forma o meio ambiente, seja por meio da utilização excessiva de insumos químicos, de recursos elétricos e hídricos, de combustíveis fósseis ou da deterioração do solo, indo em direção contrária à proposta para o alcance da sustentabilidade. -10 $^{8-10}$ 
Wilkins ${ }^{11}$ propõe em seu trabalho o termo "civic dietetics" (tradução livre: "nutrição civil"), assumindo que as externalidades que permeiam as escolhas alimentares e as forças políticas e econômicas que moldam o sistema alimentar são tão legítimas à prática nutricional quanto os conhecimentos sobre nutrientes e a relação entre alimentação e saúde. ${ }^{11}$ A autora sugere que a prática nutricional deve promover um novo sistema alimentar; sustentável, justo, economicamente viável e baseado na comunidade.

Tendo isso em vista, esclarecer as atribuições e contribuições do nutricionista para o alcance do desenvolvimento sustentável, investigando as concepções, valoração, aplicabilidade e dificuldades percebidas nesse tema, permite fomentar o papel desse profissional na promoção de um futuro de qualidade social, ambiental e econômica. O estudo baseou-se na hipótese de que a atuação profissional do nutricionista voltada para a sustentabilidade, ainda que declarada como importante, é pouco desenvolvida, indicando a necessidade de mudanças na formação e atuação profissional.

\section{Metodologia}

O estudo tem natureza descritiva e transversal, com abordagem quantitativa, e foi realizado no período de março de 2011 a junho de 2012. O projeto foi analisado e aprovado pelo Comitê de Ética e Pesquisa da Faculdade de Ciências da Saúde da Universidade de Brasília. Os dados da pesquisa foram obtidos por meio de um questionário online, estruturado e autoaplicável. Os profissionais foram convidados por meio de listas de e-mails e grupos de redes sociais. Para responder ao questionário, o participante deveria clicar no link que o encaminharia para o Termo de Consentimento Livre e Esclarecido (TCLE) da pesquisa. Ao concordar com o TCLE, o questionário era disponibilizado para preenchimento. Este instrumento era composto por 15 perguntas fechadas que abordavam aspectos que permitiam caracterizar as percepções e práticas dos nutricionistas a respeito da sustentabilidade e do sistema alimentar, e uma questão aberta para comentários, críticas, elogios ou sugestões.

As variáveis que compuseram o questionário foram: sexo, idade, cidade e estado de residência, área de atuação, tempo de formação, titulação, importância dada à sustentabilidade na atuação do nutricionista, preocupação em praticar ações sustentáveis no trabalho, percepção do impacto das ações praticadas no meio ambiente e economia local, tipos de ações sustentáveis e frequência com que são praticadas, fatores que dificultam a prática das ações e percepção da capacitação do nutricionista em atuar a favor do sistema alimentar e do desenvolvimento sustentável.

O banco de dados foi organizado por meio do programa Microsoft Excel (2010) e analisado estatisticamente por meio do programa SPSS v. 20, utilizando o teste não paramétrico qui-quadrado e a correlação de Spearman. Os dados foram considerados estatisticamente significativos quando $\rho<0,05$. 


\section{Resultados}

A amostra final foi composta por 192 nutricionistas que atenderam aos critérios de inclusão do estudo. A amostra contou com $98 \%$ de nutricionistas, do sexo feminino $(n=188)$ e idade média de 30 anos (M: 30,2; DP: 8,3). Profissionais de 16 estados do Brasil participaram do estudo. Quanto ao tempo de formação, a moda foi de dois anos. Em relação à titulação, 30\% (n=57) declararam não possuir nenhum outro tipo de titulação além da graduação, enquanto daqueles que responderam positivamente $(n=135)$, a maioria $(66 \% ; n=80)$ declarou ser especialista em Nutrição; $26 \%(n=32)$ disseram ter mestrado e $8 \%(n=10)$ declararam ter doutorado. A área de atuação mais citada no estudo foi a Clínica, seguida da Saúde Coletiva. A figura 1 apresenta as principais áreas de atuação dos nutricionistas participantes. Os nutricionistas que escolheram a opção "outro" citaram como área de atuação: alimentação escolar, consultoria, hotelaria, home care, gastronomia e gerência de restaurantes populares.

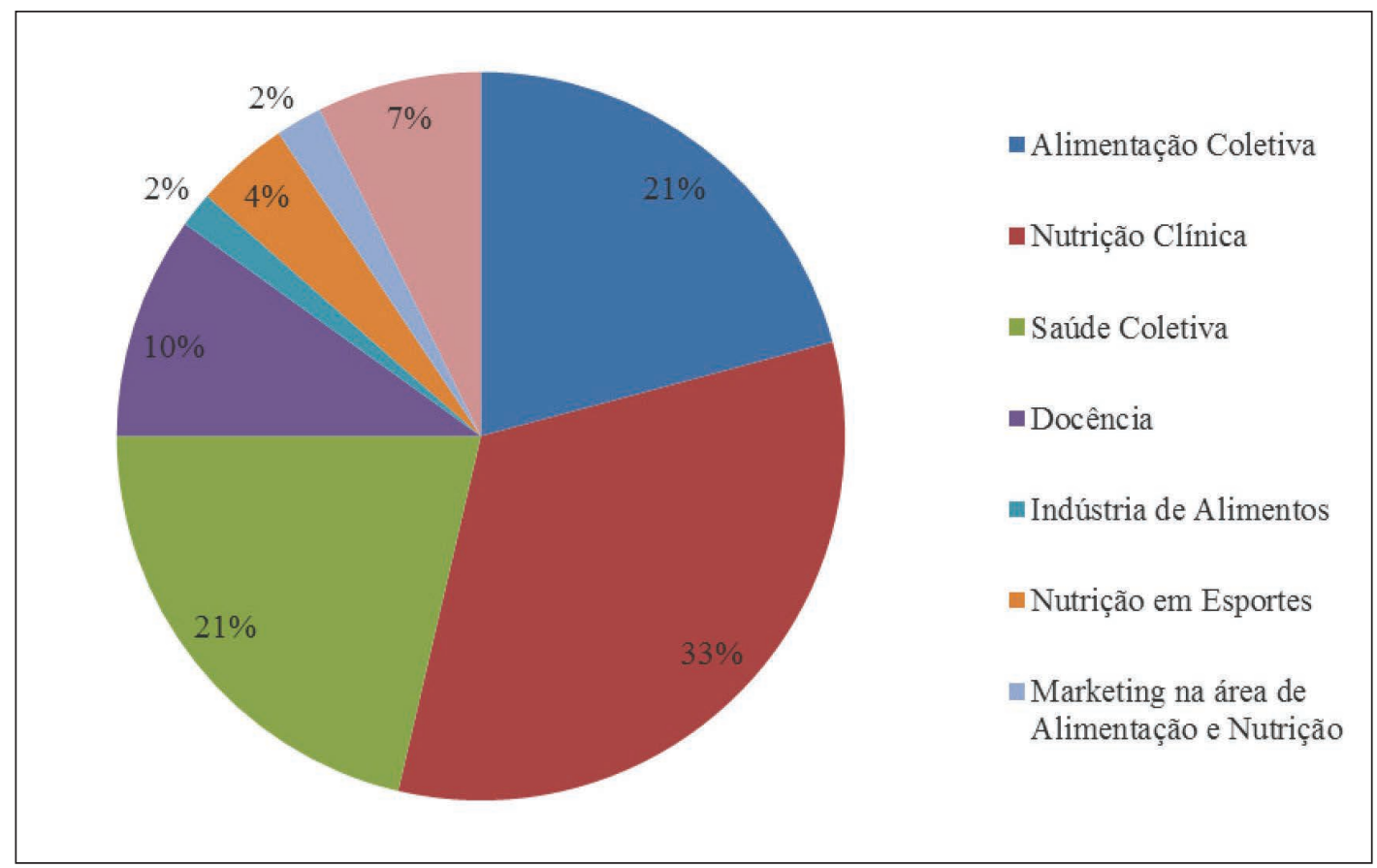

Figura 1. Distribuição dos nutricionistas participantes do estudo em relação à principal área de atuação. Brasília-DF, 2012. 
Os participantes responderam, utilizando uma escala de cinco pontos, atribuindo 1 "nada importante" e 5 "importantíssimo", ao quanto consideravam importante o tema "Desenvolvimento sustentável" na atuação do nutricionista. Os resultados estão dispostos na figura 2.

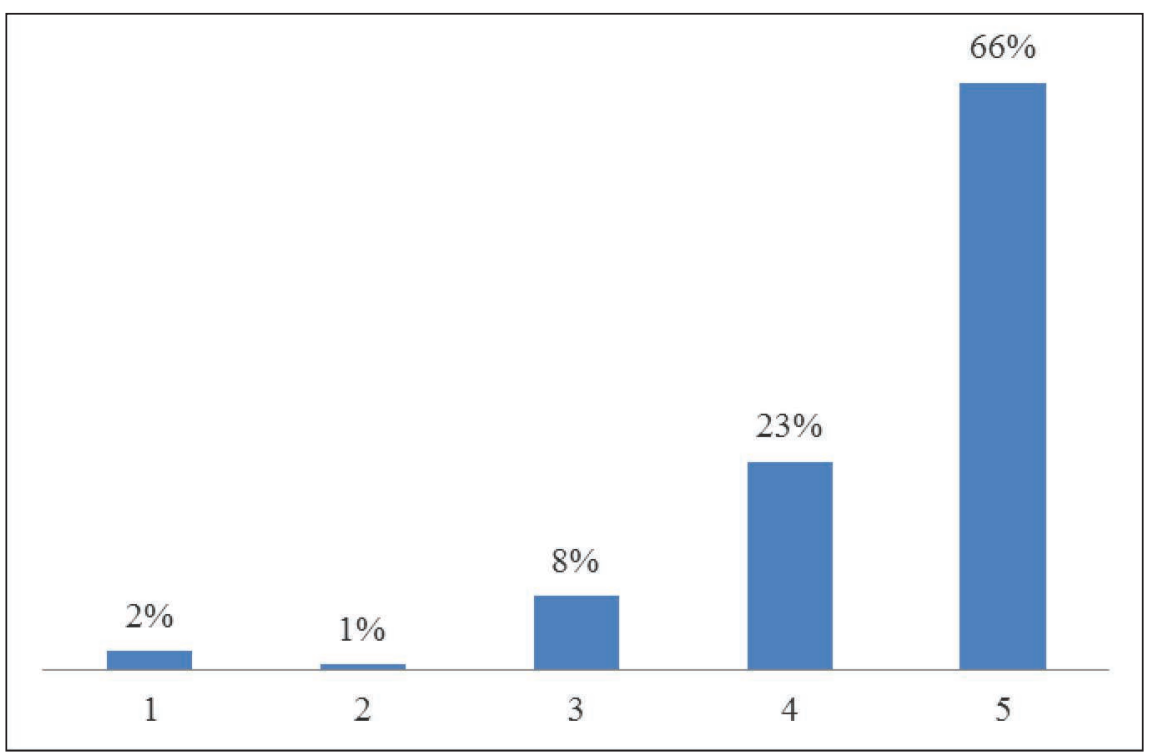

Figura 2. Importância do tema "Desenvolvimento Sustentável" na atuação do nutricionista. Brasília-DF, 2012.

Investigou-se também o grau de preocupação dos nutricionistas em relação à prática de atividades sustentáveis no trabalho. A resposta baseava-se numa escala de concordância de cinco pontos, sendo as opções "concordo totalmente", "concordo parcialmente", "nem concordo nem discordo", "discordo parcialmente" e "discordo totalmente" pontuadas, respectivamente, de 5 a 1. Os resultados estão disponíveis na figura 3. 


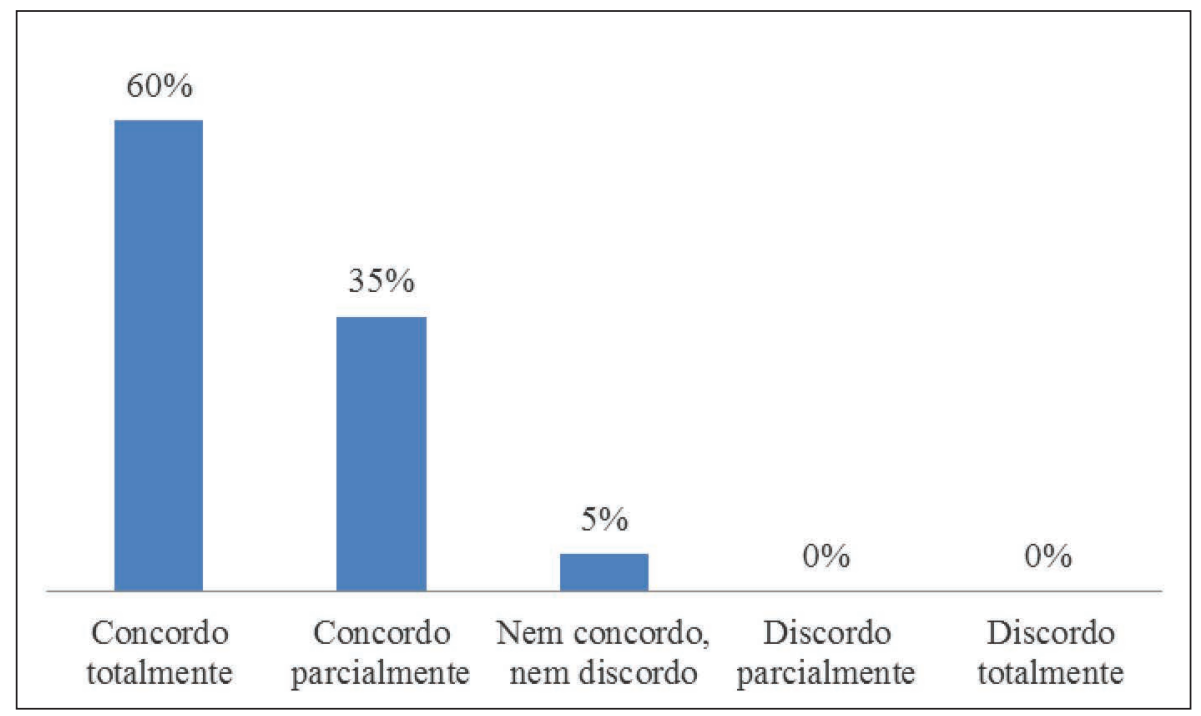

Figura 3. Grau de concordância dos nutricionistas participantes do estudo em relação à preocupação em praticar ações sustentáveis no trabalho. Brasília-DF, 2012.

Ainda utilizando a escala de concordância de cinco pontos, os participantes indicaram suas percepções acerca do impacto positivo da prática de ações sustentáveis em seu trabalho no meio ambiente e na economia local de sua cidade. A figura 4 apresentam os resultados. 


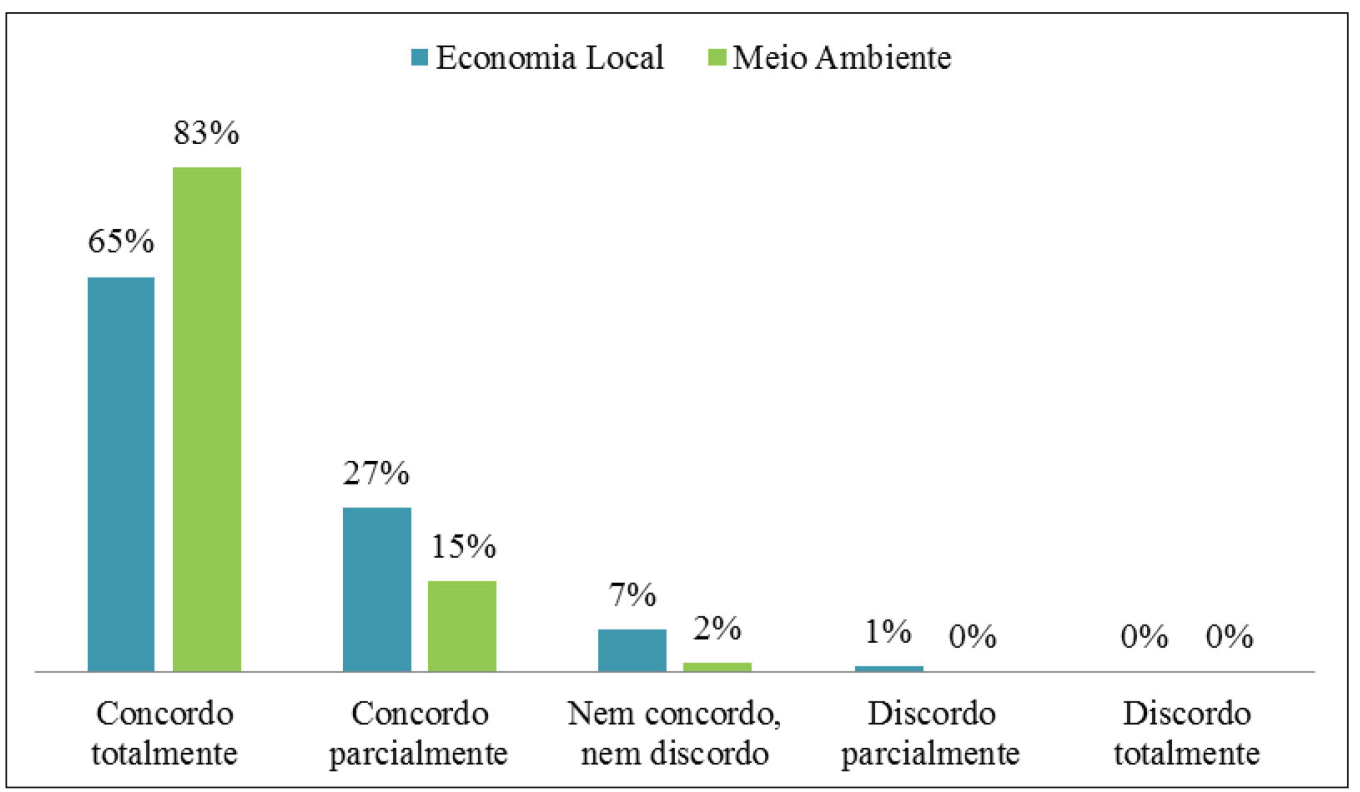

Figura 4. Percepção dos nutricionistas participantes do estudo em relação ao impacto positivo da prática de ações sustentáveis realizadas no trabalho sobre a economia local e o meio ambiente. Brasília-DF, 2012.

Solicitou-se que os participantes do estudo assinalassem a frequência com que praticaram ações sustentáveis em seu trabalho nos últimos 12 meses. Foram apresentadas 14 opções possíveis e uma opção nomeada "outro". Os participantes deveriam assinalar a frequência com que realizavam essas ações de acordo com as opções "sempre”, "às vezes", "nunca” e "não se aplica”. A figura 5 mostra os resultados dessa questão. 


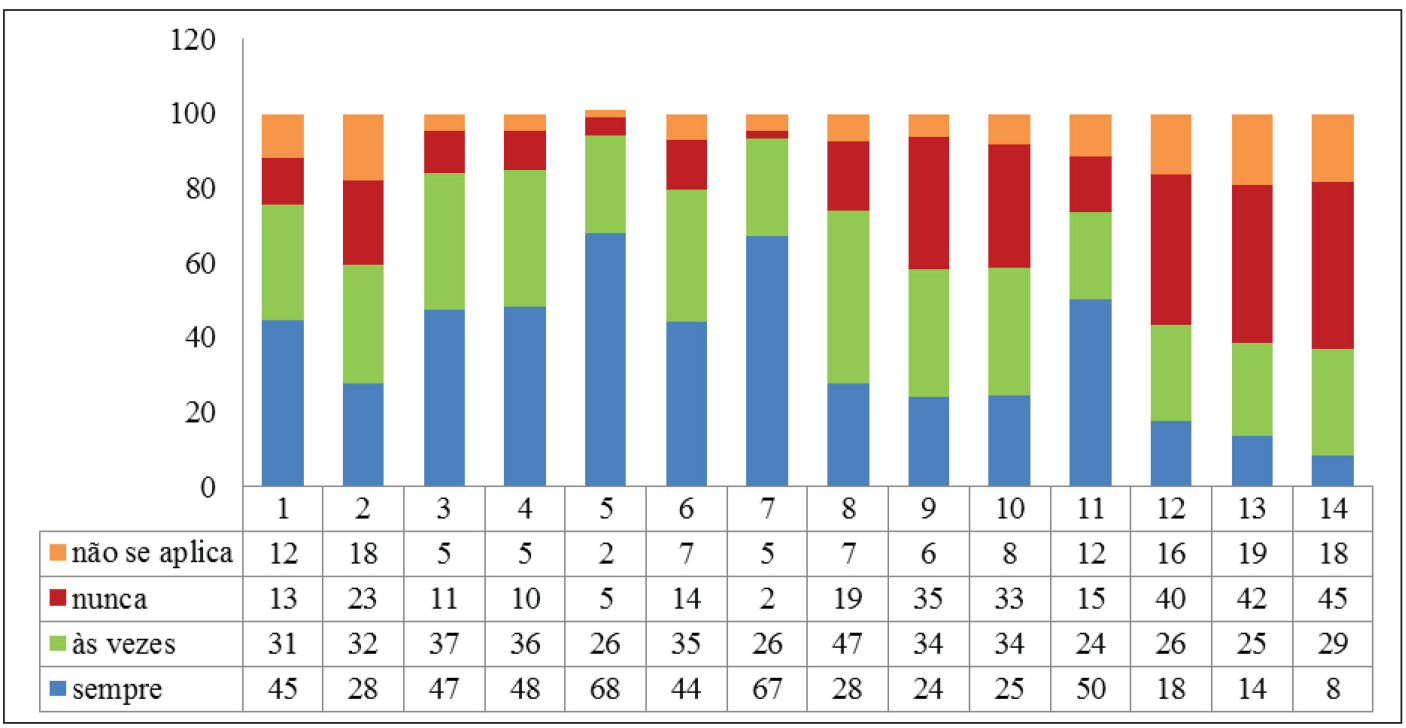

Figura 5. Frequência com que os nutricionistas participantes do estudo praticaram ações sustentáveis em seu trabalho nos últimos 12 meses. Brasília-DF, 2012.

Legenda: 1) Coleta seletiva do lixo; 2) Reciclagem do lixo; 3) Conscientização de funcionários/ clientes/ pacientes/ alunos para a redução do desperdício de energia (utilização racional de luz e equipamentos eletrônicos); 4) Conscientização de funcionários/ clientes/ pacientes/ alunos para a redução do desperdício de água; 5) Conscientização de funcionários/ clientes/ pacientes/ alunos para redução do desperdício de gêneros alimentícios; 6) referência ou incentivo pela compra de alimentos de produção regional e/ou familiar; 7) Preferência ou incentivo pela compra de alimentos de acordo com a sazonalidade; 8) Preferência ou incentivo pela compra de alimentos orgânicos; 9) Preferência ou incentivo pela compra de produtos que gerem menor resíduo de embalagem; 10) Preferência ou incentivo pela compra de produtos com embalagem reutilizável; 11) Destinação diferenciada para óleo de cozinha utilizado; 12) Desenvolvimento/ Incentivo de pesquisas que tratem do tema "desenvolvimento sustentável"; 13) Preparo de aulas/ palestras que tratem do tema "desenvolvimento sustentável"; 14) Promoção de eventos, feiras, congressos e/ou conferências que discutam o desenvolvimento sustentável e a Nutrição.

A fim de identificar as dificuldades encontradas pelos nutricionistas em praticar ações sustentáveis no local de trabalho, questionou-se quais seriam os três fatores que mais dificultavam tal prática. Os resultados podem ser vistos na figura 6 . 


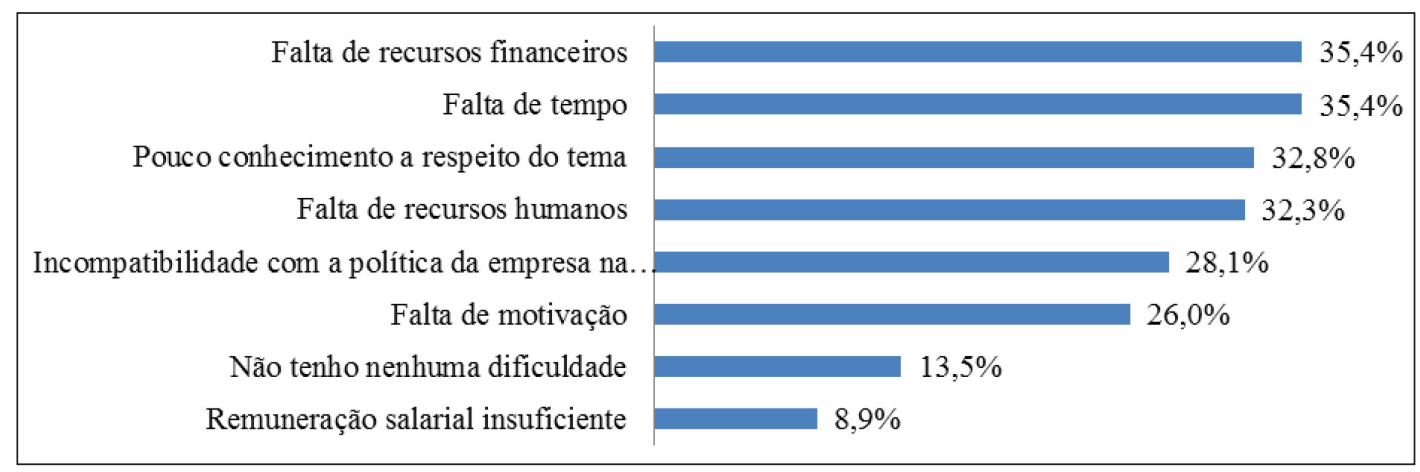

Figura 6. Percepção dos nutricionistas participantes em relação aos três principais fatores que dificultam a prática de ações sustentáveis no trabalho. Brasília-DF, 2012.

Os participantes também opinaram sobre questões relativas à contribuição da atuação do nutricionista para tornar o sistema alimentar sustentável e à capacidade do nutricionista em contribuir de forma ativa para o alcance do desenvolvimento sustentável, utilizando a escala de concordância de cinco pontos. O resultado médio das questões supracitadas foi igual, 4,8 (DP $\pm 0,4)$, demonstrando que os participantes acreditam na capacidade do profissional em contribuir para a modificação do sistema alimentar e para o alcance do desenvolvimento sustentável.

\section{Discussão}

De acordo com os resultados encontrados no estudo, os nutricionistas compreendem a importância da inserção da sustentabilidade em sua atuação profissional (M: 4,5; DP: 0,7) e dizem se preocupar em praticar ações sustentáveis no trabalho (M: 4,5; DP: 0,6). Além disso, os profissionais alegaram perceber os impactos positivos das ações sustentáveis praticadas em seu trabalho, no meio ambiente (M:4,8; DP: 0,4) e na economia local (M: 4,5; DP: 0,7). Observa-se que os nutricionistas percebem mais facilmente os impactos positivos no meio ambiente ("concordo totalmente" $=82,8 \%$; "concordo parcialmente" $=15,6 \%$ ) do que os mesmo impactos na economia local ("concordo totalmente" = 64,6\%; "concordo parcialmente" $=27,1 \%$ ). Tais resultados podem estar relacionados à noção unidimensional de que sustentabilidade diz respeito somente ao meio ambiente e que os impactos de ações ditas sustentáveis afetarão apenas essa dimensão.

Nascimento ${ }^{1}$ e outros autores abordam a noção das três dimensões que englobam o conceito de desenvolvimento sustentável - econômica, social e ambiental - que remetem à ideia de que a sustentabilidade no contexto do desenvolvimento não está relacionada somente à esfera ambiental, 
mas também às esferas econômica e social, de forma integrada. As dimensões econômica e ambiental dizem respeito à capacidade de produção e consumo eficientes, mas de forma a não alterar o equilíbrio ecológico, garantindo a utilização racional dos recursos naturais. Por sua vez, a dimensão social relaciona-se à ideia de que a sustentabilidade deve contemplar a equidade social e a qualidade de vida dessa geração e das próximas, trazendo a noção de ética e solidariedade. ${ }^{1}$ É importante perceber que a dimensão social apresenta-se como fundamental no contexto do desenvolvimento sustentável, uma vez que representa sua própria finalidade - garantir aos indivíduos uma vida justa, saudável e em harmonia com a natureza., ${ }^{2,12}$ Tendo isso em vista, pode-se vislumbrar o papel essencial da saúde e dos profissionais dessa área no contexto da sustentabilidade.

No estudo, a maioria dos participantes (67\%) alegou praticar ações sustentáveis em seu trabalho "sempre” ou "às vezes", enquanto apenas 22\% alegaram "nunca” praticá-las. No entanto, percebese que as ações já postas como usuais na atuação do nutricionista, como a conscientização para a redução do desperdício de gêneros alimentícios ("sempre" $=68 \%$ ) e a preferência ou incentivo pela compra de alimentos de acordo com a sazonalidade ("sempre" =67\%), apresentaram frequência de prática maior que aquelas ainda não consideradas como tal, a exemplo da preferência ou incentivo pela compra de produtos que gerem menor resíduo de embalagem ("sempre" = 24\%) e a promoção de eventos, feiras, congressos e/ou conferências que discutam o desenvolvimento sustentável e a Nutrição ("sempre" = 8\%).

Ainda não há outros estudos que pesquisem a atuação do nutricionista em relação às praticas sustentáveis realizadas no trabalho; assim, apesar de alguns comentários criticarem a falta de participação do nutricionista em prol do desenvolvimento sustentável, o estudo demonstra que a maioria tem interesse pelo tema e consegue inserir a sustentabilidade em seu contexto de trabalho, ainda que de forma superficial.

As ações sustentáveis mencionadas no estudo não esgotam o elenco de ações possíveis e necessárias. Elas representam apenas algumas opções e servem para auxiliar e instigar os nutricionistas a buscarem novas formas para uma atuação profissional voltada à sustentabilidade. A maioria das ações propostas contempla todas as áreas de atuação dos nutricionistas; há algumas ações mais específicas para certas áreas, mas é importante perceber que a prática de ações sustentáveis no trabalho não está restrita a apenas algumas áreas de atuação e que não significa somente reciclar o lixo ou economizar água. Como exemplos de outras possíveis ações, tem-se o apoio à agroecologia e produção orgânica e à regulamentação da publicidade de alimentos e bebidas não alcoólicas para crianças. A primeira ação diz respeito à extinção dos agrotóxicos e transgênicos da alimentação e o fim da monocultura e latifúndios, dando oportunidade a pequenos produtores agrícolas participarem do sistema alimentar, gerando sustentabilidade ambiental e justiça social; ${ }^{13}$ a segunda diz respeito a prevenir que as crianças sejam expostas aos mecanismos de mercado, evitando o desenvolvimento precoce da cultura do consumismo, que representa o oposto da cultura da sustentabilidade. 
Pode-se não perceber claramente, mas a luta contra a fome mundial, sempre considerada prioritária na atuação do nutricionista, também pode ser considerada como ação em prol da sustentabilidade. Josué de Castro alertava há décadas que a fome é a expressão biológica de males sociais, ligada intimamente às distorções econômicas - e tal assertiva ainda é verídica nos dias de hoje. Aproximadamente 925 milhões de pessoas no mundo não se alimentam de maneira suficiente e adequada, o que significa que uma em cada sete pessoas dorme com fome todas as noites ${ }^{14}$ e as evidências apontam que as mudanças climáticas e o aumento do preço dos alimentos, devido à variação do preço do petróleo, aumentarão essa estatística. ${ }^{15,16}$ A erradicação da fome não deve estar separada de outros desafios globais, tais como reestruturar economias nacionais, proteger recursos naturais da degradação e adaptar-se às mudanças climáticas. ${ }^{14}$ Percebem-se aqui com clareza as dimensões indissociáveis da sustentabilidade e ressalta-se a questão: como repensar o modelo de desenvolvimento econômico e o sistema alimentar fazendo-os sustentáveis?

A dieta ocidental padrão é composta por cereais altamente refinados, grandes quantidades de proteína animal e poucos alimentos fontes de vitaminas, minerais e fibras. ${ }^{17}$ É representada por alimentos sabidamente contaminados por diversos tipos de agrotóxicos e de baixa qualidade e pouco valor nutricional. Sabe-se também que essa combinação ameaça a saúde, aumentando o risco de, entre outros, desenvolver doenças crônicas não transmissíveis, como obesidade, diabetes, hipertensão arterial sistêmica, doenças cardiovasculares e câncer. ${ }^{18-21}$ Segundo Poubel, ${ }^{22}$ essa situação é mantida por uma força homogeneizadora dos hábitos alimentares característica do mundo globalizado, onde os países detentores das tecnologias de produção disseminam sua cultura alimentar por meio de mecanismos mercadológicos. Tendo isso em vista, pode-se identificar o papel central que o Nnutricionista pode desempenhar em favor da sustentabilidade.

Os resultados do estudo demonstram que os participantes concordam com a capacidade do nutricionista em transformar o sistema alimentar convencional num sistema sustentável (M: 4,8; DP: 0,4), bem como contribuir de forma ativa para o alcance de um modelo de desenvolvimento igualmente sustentável (M: 4,8; DP: 0,4). Wilkins \& Preuss ${ }^{11,23}$ apontam a atuação do nutricionista como chave para alcançar o desenvolvimento sustentável, uma vez que esse profissional representa o elo entre sociedade e sistema alimentar. Maluf ${ }^{24}$ cita o abismo cada vez mais visível existente entre as etapas de produção e consumo do sistema alimentar, alertando que esta pode ser a causa de muitos problemas alimentares atuais. Portanto, reduzir tal abismo, expondo à sociedade suas causas e consequências e impulsionando-a a agir de forma incisiva no processo de mudança da configuração desse sistema, é função do nutricionista, profissional capacitado a compreender o alimento em relação à sua composição nutricional, bem como todo o arcabouço contextual socioeconômico no qual este está inserido, considerando que o comer é, antes de tudo, um ato político e ideológico. ${ }^{11,25}$ 
No entanto, os resultados demonstram que, para atuar profissionalmente de forma sustentável, o nutricionista percebe como entraves a falta de tempo (35\%), de recursos financeiros (35\%) e de conhecimento acerca de sustentabilidade (32\%). Os dois primeiros entraves podem ser explicados pela relação entre a carga horária de trabalho exigida do nutricionista (em um contrato convencional 40h/semana) e a remuneração salarial média ( $\mathrm{R}$ \$ 1.600), raramente considerada justa pelos profissionais. ${ }^{26} \mathrm{O}$ terceiro entrave, pouco conhecimento acerca de sustentabilidade, pode ser entendido como uma falha ainda na formação profissional e/ou na pós-graduação.

Diversos estudos que investigam a formação profissional do nutricionista demonstram falhas na estrutura da graduação em termos de conteúdo e metodologia; ${ }^{27}$ além disso, não há no Brasil nenhum curso de pós-graduação em Nutrição que trate especificamente de sustentabilidade. Ainda de acordo com os resultados, $30 \%$ dos nutricionistas participantes do estudo alegaram não ter nenhuma outra titulação além da graduação e apenas $18 \%$ disseram desenvolver ou incentivar pesquisas que tratem do tema do desenvolvimento sustentável, fatores que incitam a falta de insumos teóricos sobre o tema dentro do contexto da Nutrição. As opções "falta de motivação" e "remuneração salarial insuficiente" foram citadas com menor frequência (26\% e 8\%, respectivamente), mas possuem relação direta com as três opções tidas como as mais dificultadoras das práticas sustentáveis no trabalho do nutricionista. Apesar dessas possíveis justificativas, sabe-se que a maioria das ações sustentáveis expostas no estudo, e muitas das demais ações, não demandam necessariamente muitos recursos financeiros ou tempo para serem realizadas, sugerindo ser a falta de conhecimento acerca do tema a maior dificuldade para a completa inserção da sustentabilidade na atuação do nutricionista.

\section{Conclusão}

Por meio deste estudo, foi possível caracterizar a atuação profissional do nutricionista segundo aspectos relativos ao sistema alimentar e à sustentabilidade. A hipótese do estudo - "a atuação profissional do nutricionista voltada para a sustentabilidade, ainda que declarada importante, é pouco desenvolvida, indicando a necessidade de mudanças na formação e atuação profissional" foi validada de acordo com os resultados encontrados. A prática de ações sustentáveis no trabalho do nutricionista demonstrou-se satisfatória, mas os dados obtidos não permitem uma análise mais aprofundada sobre a forma como as ações são executadas e sua representatividade na atuação desse profissional.

Os problemas que concernem ao alcance do desenvolvimento sustentável são sistêmicos, e indicam a necessidade de soluções igualmente sistêmicas. Assim, em tempos de crises econômica e ambiental, já não é mais suficiente atuar individual e isoladamente. Tendo isso em vista, o nutricionista deve construir seus conhecimentos de forma integrada e holística, a fim de trabalhar 
a alimentação, a nutrição, a saúde e a sustentabilidade em prol da sociedade e em termos de inter e transdisciplinaridade. E ainda, de forma multiprofissional, pois os desafios que permeiam a concretização do desenvolvimento sustentável são grandiosos, e demandam esforços multilaterais, empoderamento e mobilização social.

Em termos de limitações, o estudo não foi completamente capaz de identificar os conhecimentos dos nutricionistas em relação ao sistema alimentar e à sustentabilidade, dado que foi realizado por meio de um questionário estruturado e com perguntas fechadas, estreitando as possibilidades de respostas e reflexões sobre o tema. Além disso, trata-se de uma amostra de conveniência, que confere dados para a geração de hipóteses, mas não de dados conclusivos.

Desta forma, sugere-se elaboração de mais estudos que investiguem os conhecimentos e práticas desses profissionais acerca da sustentabilidade, e a reformulação da formação e atuação profissional do nutricionista, a fim de esclarecer possíveis contribuições desse profissional para o alcance da sustentabilidade ambiental, econômica e social.

\section{Referências}

1. Nascimento EP. Trajetória da sustentabilidade: do ambiental ao social, do social ao econômico. Rev. Estudos Avançados. 2012; 26(74):51-64.

2. Haines A, Alleyne G, Kickbusch I, Dora C. From the earth summit to Rio+20: integration of health and sustainable development. Lancet. 2012; 379(9832):2189-97.

3. The Lancet. Sustainable development for health: Rio and beyond. Lancet. 2012; 379(9832):2117.

4. Brundtland G. Our common future. Oxford: Oxford Press; 1987.

5. Pereira AC, Silva GZ, Carbonari MEE. Sustentabilidade, responsabilidade social e meio ambiente. São Paulo: Saraiva; 2011.

6. Maluf R, Belik W. Abastecimento e segurança alimentar: os limites da liberalização. Campinas: Unicamp; 2000.

7. Brasil. Lei no 11.346, de 15 de setembro de 2006. Cria o Sistema Nacional de Segurança Alimentar e Nutricional - Sisan com vistas em assegurar o direito humano à alimentação adequada e dá outras providências. Diário Oficial da União. 18 set 2006.

8. University of Michigan. Center For Sustainable Systems. U.S. food system. U.S. Food System Factsheet. Oct. 2010. Pub. No. CSS01-06.

9. Kaufman J, Kameshwari P. The food system: a stranger to the planning field. APA Journal. 2000; 66(2):113-124. 
10. Preuss, K. Impacto do sistema de produção de alimentos no meio ambiente. Webartigo. 03 nov. 2009. [acesso em 28 abr. 2011]. Disponível em: http://www.webartigos.com/artigos/impacto-do-sistemade-producao-de-alimentos-no-meio-ambiente/27435/

11. Wilkins JL. Civic dietetics: opportunities for integrating civic agriculture concepts into dietetic practice. Agric. Hum. Values. 2009; 26:57-66.

12. Sachs I. Caminhos para o desenvolvimento sustentável. Rio de Janeiro: Gramond; 2009.

13. Badue AFB. Inserção de hortaliças e frutas orgânicas na merenda escolar: as potencialidades da participação e as representações sociais de agricultores de Parelheiros. [dissertação]. São Paulo: Faculdade de Saúde Pública, Universidade de São Paulo; 2007.

14. Silva JG. Says fight against hunger must be linked to other global challenges. Roma: Food and Agriculture Organization of the United Nations; 1 jan. 2012. [acesso em 15 jun. 2013]. Disponível em: http://www.fao.org/news/story/en/item/117486/icode/

15. Parry M, Evans A, Rosegrant MW, Wheeler T. Climate change and hunger: responding to the challenge. Itália: World Food Programme; 2009.

16. Bailey R. Crescendo para um futuro melhor. Justiça alimentar em um mundo de recursos limitados. Oxfam Internacional; 2011.

17. Instituto Brasileiro de Geografia e Estatística. Pesquisa de orçamentos familiares 2008-2009: análise do consumo alimentar pessoal no Brasil. Rio de Janeiro: IBGE; 2011.

18. Associação Brasileira de Saúde Coletiva. Dossiê ABRASCO: um alerta sobre os impactos dos agrotóxicos na saúde. $1^{\text {a }}$ parte. Rio de Janeiro: Abrasco; 2012.

19. Castro Neto N, Denuzi VSS, Rinaldi RN, Staduto JAR. Produção orgânica: uma potencialidade estratégica para a agricultura familiar. Revista Percurso- Nemo. 2010; 2(2): 73-95.

20. Siqueira SL, Kruse MHL. Agrotóxicos e saúde humana: contribuição dos profissionais do campo da saúde. Rev. Esc. Enferm. 2008; 43(3):584-90.

21. Toassa EC, Machado EH, Szarfarc SC,Philippe S, Leal GVS. Alimentos orgânicos e o meio ambiente. Nutrire: Rev. Soc. Bras. Alim. Nutr. 2009; 34(1):175-84.

22. Poubel RO. Hábitos alimentares, nutrição e sustentabilidade: Agroflorestas sucessionais como estratégia na agricultura familiar. [dissertação]. Brasília: Universidade de Brasília, Centro de Desenvolvimento Sustentável; 2006.

23. Preuss K. Integrando nutrição e desenvolvimento sustentável: atribuições e ações do nutricionista. Netsaber. [acesso em: 5 mar. 2011]. Disponível em: http://artigos.netsaber.com.br/resumo_ artigo_19289/artigo_sobre_integrando_nutricao_e_desenvolvimento_sustentavel:_atribuicoes_e_ acoes_do_nutricionista.

24. Maluf R. Recursos naturais e soberania alimentar. In: Congresso Virtual Internacional- Economia verde e Inclusão Socioprodutiva: o papel da agricultura familiar. 13-22 jun. 2012; Rio de Janeiro; Brasil. Brasília: Ministério do Meio Ambiente; 2012. [acesso em 16 abr. 2012]. Disponível em: http:// www.congressorio20.org.br/sitio/seguridad-alimentaria.html. 
25. Portilho F, Castañeda M, Castro IRR. Alimentação no contexto contemporâneo: consumo, ação política e sustentabilidade. Cien. Saúde Coletiva. 2011; 16(1):99-106, 2011.

26. Akutsu RCCA. Valores e bem-estar dos nutricionistas brasileiros [tese]. Brasília: Universidade de Brasília, Faculdade de Ciências da Saúde; 2008.

27. Ceccim RB, Feuerwerker LCM. Mudanças na graduação das profissões de saúde sob o eixo da integralidade. Cad. Saúde Pública. 2004; 20(5):1400-1410.

Recebido: 03/6/2013

Revisado: 02/11/2013

Aprovado: 28/11/2013 